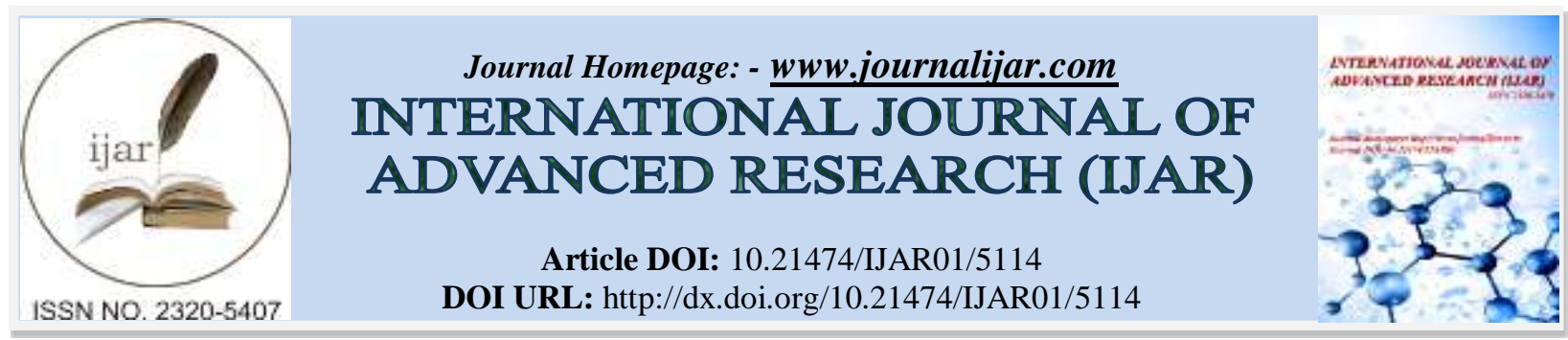

RESEARCH ARTICLE

\title{
THIDIAZURON - INDUCED HIGH FREQUENCY SHOOT REGENERATION FROM LEAF AND NODE DERIVED CALLUS OF PUERARIA TUBEROSA DC, WILLD, A MEDICINALLY IMPORTANT WOODY CLIMBER.
}

\section{Dr. V. Sadguna ${ }^{1}$ and ${ }^{*}$ Dr. Md. Mustafa ${ }^{2}$.}

1. Doctor of Philosophy in Botany, Department of Botany, Kakatiya University, Warangal, 506009, Telangana State, India.

2. Assistant Professor in Botany, Department of Botany, Kakatiya University, Warangal, 506009, Telangana State, India.

\section{Manuscript Info}

\section{Manuscript History}

Received: 09 June 2017

Final Accepted: 11 July 2017

Published: August 2017

\section{Key words:-}

Pueraria tuberosa, leaf callus, node callus, growth regulators, in vitro regeneration, rooting, hardening and acclimatization.

\begin{abstract}
An efficient protocol is developed for the induction of shoot regeneration from leaf and node derived callus of Pueraria tuberosa on MS medium supplemented with TDZ (Thidiazuron) $(2.0 \mathrm{mg} / \mathrm{l})$ and IAA $(1.0 \mathrm{mg} / \mathrm{l})$ after two of subsequent subcultures. This is the first report of its kind in this plant of Pueraria tuberosa. It is belongs to member of Paplionaceae family. The obtained shoots were elongated after four weeks on the same medium and induced roots by transferring the cultures on half strength MS medium supplemented with $3.0 \mathrm{mg} / \mathrm{l}$ IBA after four weeks of inoculation. These plantlets were allowed for hardening and acclimatization for field transfer.
\end{abstract}

Copy Right, IJAR, 2017,. All rights reserved.

\section{Introduction:-}

Pueraria tuberosa is commonly known as Indian kudzu. Pueraria tuberosa is widely spread over China, Japan, India and Pakistan. Kudzu is adapted to a wide range of soil types are acidic, rocky mountainous and fertile lowland soils (Whyte $e$ al., 1953; Skerman, 1977; Duke, 1981). It is an important medicinal plant in traditional system of medicine in Ayurveda. It has been used to effect on vascular smooth muscle tissue cardiovascular risk factor and cerebrovascular fibrinolysis (Kashyap et al., 2005). It is used for neurological and psychiatric disorder and lung diseases (Kusano and Ferrani, 2008), kidney failure and cancer stage I and II (Bingham et al., 1998). Pueraria tuberosa tubers are used as anti-rheumatic, diuretic and immune booster (Khare, 2007 and Puri, 2003). The vegetative mode of propagation by using root tubers of Pueraria tuberosa is a major hurdle for its development. As it has been used for various ailments it becomes vulnerable. Till to date there is no proper protocol for the regeneration of plantlets for use. For, this we have developed a protocol for the high frequency regeneration of plantlets from leaf and node derived callus of Pueraria tuberosa by using TDZ and IAA in MS medium with repeated subcultures.

\section{Materials And Methods:-}

Explant sterilization: Young leaves and nodal explants of Pueraria tuberosa were collected from the 2 years old plant from research field of Botany Department. These explants were washed under running tap water for 10-15 minutes and surface sterilized with $0.1 \% \mathrm{Hgcl}_{2}$ for 5-6 minutes, rinsed 3-4 times with sterilized distilled water. After sterilization leaf and node explants were cut into small pieces and inoculated on MS medium supplemented with 
different concentrations and combinations of auxins and cytokinins and casein hydrolysate. The $\mathrm{P}^{\mathrm{H}}$ of the medium was adjusted to 5.8 before the addition of agar agar and culture medium was autoclaved at $121^{\circ} \mathrm{C}$ with $15 \mathrm{Lbs}$ pressure for 20 minutes. After inoculation all culture tubes were incubated at $25 \pm 2{ }^{\circ} \mathrm{C}, 16 \mathrm{hrs} \mathrm{light} / 8 \mathrm{hrs}$ dark of photoperiod with illumination of 1500-3500 lux fluorescent tube lights.

\section{Resuls:-}

Callus induction: leaf and node explants of Pueraria tuberosa were cultured on MS medium fortified with 2, 4-D, NAA and IAA alone and incombination with BAP. Different types of calli were produced from leaf and node explants after two subcultures each with four weeks. Green compact callus was induced on MS medium fortified with $2.5 \mathrm{mg} / 1 \mathrm{IAA}+2.0 \mathrm{mg} / \mathrm{l} \mathrm{BAP}$ and $2.0 \mathrm{mg} / \mathrm{l} \mathrm{NAA}+2.0 \mathrm{mg} / \mathrm{l} \mathrm{BAP}$. This callus was utilized for further regeneration studies.

\section{In Vitro Shoot Regeneration:- Effect of BAP, Kn, TDZ incombination with IAA:-}

Green compact callus of leaf and node derived callus of $P$. tuberosa was cultured on MS medium supplemented with $2.5 \mathrm{mg} / 1 \mathrm{BAP}+1.0 \mathrm{mg} / \mathrm{l} \mathrm{IAA}$ for the induction of shoots. Few small sized shoot buds were developed after four weeks of culture from leaf and node derived callus. These buds were developed into shoots after two weeks of culture on the same medium after one passage (Table-1, Fig-1a). The mean number of shoots were higher from leaf derived callus than node derived callus. Higher mean number of shoots $(4.42 \pm 0.34)$ were achieved from node derived callus on MS medium fortified with $2.0 \mathrm{mg} / \mathrm{l} \mathrm{Kn}+1.0 \mathrm{mg} / \mathrm{IAA}$ of $P$. tuberosa (Fig-1).

The most effective $(5.12 \pm 0.23)$ in vitro shoot bud regeneration was achieved from leaf derived callus on MS medium fortified with $2.0 \mathrm{mg} / 1 \mathrm{TDZ}+1.0 \mathrm{mg} / \mathrm{l}$ IAA after two passages. The higher and lower concentration of TDZ did not promote in the proliferation of shoot buds in Pueraria tuberosa (Table-1, Fig-1b).

\section{Effect of BAP, NAA, IAA incombination with Casein hydrolysate:-}

When the callus was inoculated on MS medium supplemented with $1.5 \mathrm{mg} / \mathrm{l} \mathrm{BAP}+200 \mathrm{mg} / \mathrm{l} \mathrm{Casein} \mathrm{Hydrolysate}$ $(\mathrm{CH})$, the callus proliferated into shoot buds without leaching of phenolic compounds after two subcultures (Table-2, Fig-2). By using the concentration of BAP was increased from $1.5 \mathrm{mg} / 1$ to $2.0 \mathrm{mg} / 1$, the mean number of shoots were increased both from leaf and node derived callus cultures (Fig-1c). The further enhancement in the mean number of shoots was achieved on MS medium supplemented with $2.0 \mathrm{mg} / 1 \mathrm{NAA}$ and $200 \mathrm{mg} / \mathrm{l} \mathrm{CH}$. MS medium fortified with IAA $(2.0 \mathrm{mg} / \mathrm{l})$ with $200 \mathrm{mg} / \mathrm{l} \mathrm{CH}$ also promoted shoot buds induction in both the cases after six weeks of culture with lower frequency. MS medium fortified with $(2.0 \mathrm{mg} / \mathrm{l}) \mathrm{NAA}$ and $(200 \mathrm{mg} / \mathrm{l}) \mathrm{CH}$ also promoted shoot buds induction from both leaf and node derived callus after six weeks of cultures. Among the all combinations and concentrations the most effective shoot bud regeneration was achieved in MS medium supplemented with TDZ incombination with IAA from leaf derived callus and NAA in combination with $\mathrm{CH}$ from node derived callus of Pueraria tuberosa.

\section{Effect of various auxins on rooting:-}

In vitro shoot cultures were used for induction of rooting. The in vitro root initiation was observed after 20-30 days of inoculation of rooting medium. We have tested different concentrations and combinations of auxins, the highest mean number of roots $(4.05 \pm 0.18)$ was observed on $1 / 2$ strength MS medium fortified with $3.0 \mathrm{mg} / \mathrm{lBA}$ in Pueraria tuberosa (Fig-1d). After rooting, plantlets were transferred for hardening and acclimatization.

\section{Hardening and Acclimatization:-}

The in vitro rooted plants with fully expanded leaves and well developed roots were removed from culture tubes, without damaging root system and rinsed with sterile distilled water to remove adhering nutrient agar-agar medium and then transferred into the polycups with compost vermin and autoclaved soil in the ratio of 1:3. The polycups were covered with polybags to maintain high humidity and kept in culture chamber. They were gradually exposed from artificial environmental conditions to natural acclimatization (Fig-1e \& 1f).

\section{Discussions:-}

The higher number of $(4.35 \pm 0.23)$ was proliferated from leaf derived callus on MS medium fortified with $2.5 \mathrm{mg} / 1$ BAP $+1.0 \mathrm{mg} / \mathrm{l}$ IAA, after four weeks of culture. Similar results were observed on MS medium fortified with BAP in combination with IAA from petiole explant of Phaseolus (Mamun et al., 2004). Veltcheva and Svetleva, 2005, 
were reported from cotyledon derived callus on MS with different concentration of BAP with IAA (Albizia lebbeck). Priyanka et al, were observed highest mean number of shoots from leaf derived callus cultures on MS medium fortified with different concentrations of BAP in combination with Kn (Psorolia corylifolia). We have observed the moderate shoot proliferation on MS medium fortified with TDZ with IAA in Pueraria tuberosa. Higher mean number of shoot buds $(5.12 \pm 0.24)$ were proliferated on MS medium supplemented with $2.0 \mathrm{mg} / \mathrm{lDZ}+1.0 \mathrm{mg} / \mathrm{l}$ IAA from leaf derived callus of Pueraria tuberosa. Similarly maximum mean number of shoots with isoflavonoids production was reported on MS with TDZ with IBA from Pueraria tuberosa (Udomusk et al., 2009). Mohamed $e t$ al (2006) were reported that the effective regeneration on MS medium supplemented with BAP with TDZ induced highest mean number of shoot formation in Phaseolus angularis. Tzitzikas et al (2004) were also observed to stimulate bud regeneration and shoot multiplication on MS medium supplemented with TDZ with BAP or any other growth hormones of Pisum sativum. Alone TDZ also proliferated shoot elongation from Psoralea corylifolia (Shinde et al., 2009).

In our investigation shoot buds were also proliferated from leaf and node callus of Pueraria tuberosa on MS medium supplemented with BAP with $\mathrm{CH}$ without leaching phenolic compound were in the medium. Vasanth et al., (2006), were observed most effective in vitro shoot regeneration on MS medium supplemented with BA (1.5 Mm) +NAA (1.0 mM) + PVP (25 Mm) from cotyledon and embryonal axes of Arachis hypogaea. Different concentrations of NAA incombination with $\mathrm{CH}$, moderate number of shoot buds observed from leaf and node derived callus of Pueraria tuberosa. Vasanth et al., (2006), were reported that the individual concentrations of BA, NAA, PVP, L-Glutamine enhanced maximum mean number of shoot multiplication of Arachis hypogaea. Similarly, the effective regeneration was observed on IAA with various amino acid in Arachis hypogaea. After regeneration of plantlets they were transferred into $1 / 2$ strength MS rooting medium for rooting. Highest roots were observed on MS medium with $3.0 \mathrm{mg} / \mathrm{l} \mathrm{IBA}$ alone after two weeks of culture. Similar results were observed on $1 / 2$ strength MS with 2.0-3.0 mg/l IBA from Chick pea (Udomusk et al., 2009). Priyanka et al., (2013) was also reported $2.5 \mu \mathrm{M}$ IBA was best result in Psorolea corylifolia.

Table-1:- In vitro shoot regeneration via indirect organogenesis from leaf and node derived callus cultured on MS with BAP, Kn and TDZ in combination with IAA in Pueraria tuberosa.

\begin{tabular}{|c|c|c|c|c|c|c|c|}
\hline \multirow{2}{*}{\multicolumn{4}{|c|}{$\begin{array}{l}\text { MS with growth regulator } \\
\text { concentration }(\mathrm{mg} / \mathrm{l})\end{array}$}} & \multicolumn{4}{|c|}{ In vitro shoot bud regeneration } \\
\hline & & & & \multicolumn{2}{|c|}{ Leaf derived callus } & \multicolumn{2}{|c|}{ Node derived callus } \\
\hline BAP & $\mathrm{Kn}$ & TDZ & IAA & $\begin{array}{l}\text { No of shoots } \\
\text { (Mean } \pm \text { S.E) }\end{array}$ & $\begin{array}{l}\text { Shoot length }(\mathrm{cm}) \\
(\text { Mean } \pm \text { S.E })\end{array}$ & $\begin{array}{l}\text { No of shoots } \\
(\text { Mean } \pm \text { S.E) }\end{array}$ & $\begin{array}{l}\text { Shoot length }(\mathrm{cm}) \\
(\text { Mean } \pm \text { S.E) }\end{array}$ \\
\hline 0.5 & -- & -- & 1.0 & -- & -- & -- & -- \\
\hline 1.0 & -- & -- & 1.0 & -- & -- & -- & -- \\
\hline 1.5 & -- & -- & 1.0 & $1.25 \pm 0.36$ & $0.45 \pm 0.30$ & -- & -- \\
\hline 2.0 & -- & -- & 1.0 & $2.01 \pm 0.34$ & $0.66 \pm 0.41$ & $1.34 \pm 0.32$ & $0.44 \pm 0.22$ \\
\hline 2.5 & -- & -- & 1.0 & $4.35 \pm 0.23$ & $1.22 \pm 0.28$ & $4.05 \pm 0.37$ & $0.95 \pm 0.33$ \\
\hline 3.0 & -- & -- & 1.0 & $2.40 \pm 0.31$ & $1.45 \pm 0.34$ & $2.05 \pm 0.38$ & $0.40 \pm 0.36$ \\
\hline-- & 0.5 & -- & 1.0 & -- & -- & -- & -- \\
\hline-- & 1.0 & -- & 1.0 & -- & -- & -- & -- \\
\hline-- & 1.5 & -- & 1.0 & -- & -- & $2.35 \pm 0.31$ & $0.52 \pm 0.31$ \\
\hline -- & 2.0 & -- & 1.0 & $1.84 \pm 0.24$ & $0.66 \pm 0.27$ & $4.42 \pm 0.34$ & $1.12 \pm 0.37$ \\
\hline-- & 2.5 & -- & 1.0 & $2.02 \pm 0.33$ & $1.04 \pm 0.33$ & $1.52 \pm 0.26$ & $1.24 \pm 0.43$ \\
\hline-- & 3.0 & -- & 1.0 & $1.25 \pm 0.39$ & $0.32 \pm 0.42$ & -- & -- \\
\hline-- & -- & 0.5 & 1.0 & -- & -- & -- & -- \\
\hline -- & -- & 1.0 & 1.0 & $2.06 \pm 0.24$ & $0.45 \pm 0.18$ & -- & -- \\
\hline -- & -- & 1.5 & 1.0 & $2.20 \pm 0.28$ & $0.84 \pm 0.22$ & -- & -- \\
\hline -- & -- & 2.0 & 1.0 & $5.12 \pm 0.23$ & $1.08 \pm 0.32$ & -- & -- \\
\hline-- & -- & 2.5 & 1.0 & $3.26 \pm 0.32$ & $0.66 \pm 0.27$ & $3.15 \pm 0.29$ & $0.22 \pm 0.27$ \\
\hline -- & -- & 3.0 & 1.0 & -- & -- & $1.01 \pm 0.32$ & $0.23 \pm 0.35$ \\
\hline
\end{tabular}

*Data was collected after six weeks 
Table-2:- In vitro shoot regeneration via indirect organogenesis from leaf and node derived callus cultured on MS with BAP, NAA and IAA in combination with CH in Pueraria tuberosa.

\begin{tabular}{|c|c|c|c|c|c|c|c|}
\hline \multirow{2}{*}{\multicolumn{4}{|c|}{$\begin{array}{l}\text { MS with growth regulator } \\
\text { concentration }(\mathrm{mg} / \mathrm{l})\end{array}$}} & \multicolumn{4}{|c|}{ In vitro shoot bud regeneration } \\
\hline & & & & \multicolumn{2}{|c|}{ Leaf derived callus } & \multicolumn{2}{|c|}{ Node derived callus } \\
\hline BAP & NAA & IAA & Casine & $\begin{array}{l}\text { No of shoots } \\
(\text { Mean } \pm \text { S.E) }\end{array}$ & $\begin{array}{l}\text { Shoot length }(\mathrm{cm}) \\
(\text { Mean } \pm \text { S.E })\end{array}$ & $\begin{array}{l}\text { No of shoots } \\
\text { (Mean } \pm \text { S.E) }\end{array}$ & $\begin{array}{l}\text { Shoot length }(\mathrm{cm}) \\
(\text { Mean } \pm \text { S.E) }\end{array}$ \\
\hline 0.5 & -- & -- & 200 & -- & -- & -- & -- \\
\hline 1.0 & -- & -- & 200 & -- & -- & -- & -- \\
\hline 1.5 & -- & -- & 200 & $1.25 \pm 0.36$ & $0.45 \pm 0.30$ & -- & -- \\
\hline 2.0 & -- & -- & 200 & $1.31 \pm 0.34$ & $0.66 \pm 0.41$ & $1.24 \pm 0.32$ & $0.34 \pm 0.24$ \\
\hline 2.5 & -- & -- & 200 & $2.15 \pm 0.20$ & $0.22 \pm 0.32$ & $2.25 \pm 0.21$ & $1.05 \pm 0.30$ \\
\hline 3.0 & -- & -- & 200 & $1.40 \pm 0.31$ & $1.25 \pm 0.34$ & $1.05 \pm 0.36$ & $1.12 \pm 0.34$ \\
\hline-- & 0.5 & -- & 200 & -- & -- & -- & -- \\
\hline-- & 1.0 & -- & 200 & -- & -- & -- & -- \\
\hline-- & 1.5 & -- & 200 & $2.20 \pm 0.28$ & $0.84 \pm 0.22$ & -- & -- \\
\hline-- & 2.0 & -- & 200 & $3.10 \pm 0.23$ & $0.40 \pm 0.32$ & $3.42 \pm 0.34$ & $1.02 \pm 0.33$ \\
\hline-- & 2.5 & -- & 200 & $1.26 \pm 0.32$ & $0.66 \pm 0.27$ & $1.12 \pm 0.26$ & $0.24 \pm 0.38$ \\
\hline-- & 3.0 & -- & 200 & -- & & -- & -- \\
\hline-- & -- & 0.5 & 200 & -- & -- & -- & -- \\
\hline-- & -- & 1.0 & 200 & -- & -- & -- & -- \\
\hline-- & -- & 1.5 & 200 & -- & -- & -- & -- \\
\hline-- & -- & 2.0 & 200 & $2.52 \pm 0.30$ & $0.34 \pm 0.26$ & $3.05 \pm 0.29$ & $0.42 \pm 0.27$ \\
\hline-- & -- & 2.5 & 200 & $1.25 \pm 0.24$ & $0.32 \pm 0.42$ & $0.15 \pm 0.32$ & $0.23 \pm 0.35$ \\
\hline-- & -- & 3.0 & 200 & -- & -- & -- & -- \\
\hline
\end{tabular}

*Data was collected after six weeks

Fig-1: In vitro shoot regeneration via indirect organogenesis from leaf and node derived callus cultured on MS with BAP, Kn and TDZ in combination with IAA in Pueraria tuberosa.

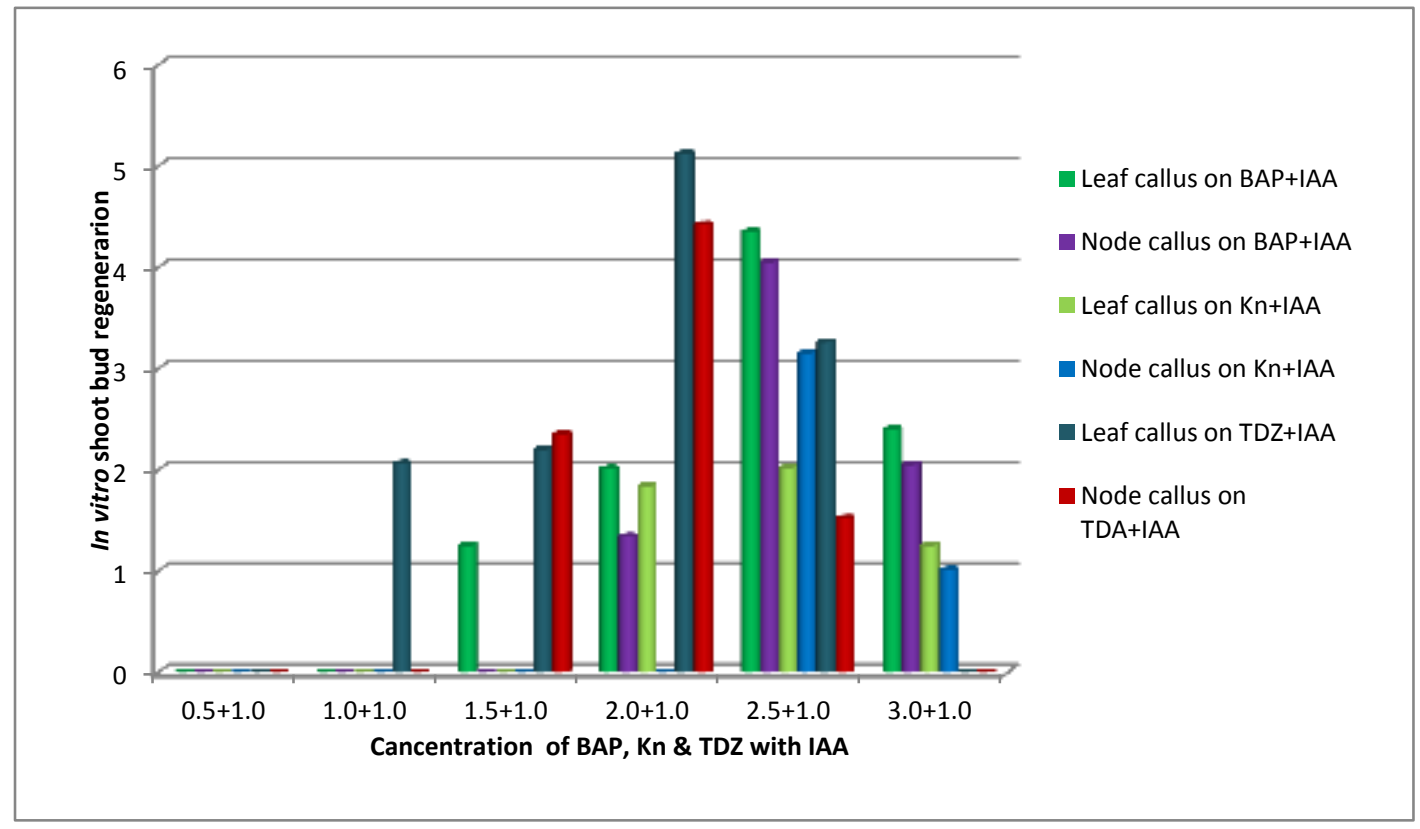


Fig 2:- In vitro shoot regeneration via indirect organogenesis from leaf and node derived callus cultured on MS with BAP, NAA and IAA in combination with $\mathrm{CH}$ in Pueraria tuberosa.

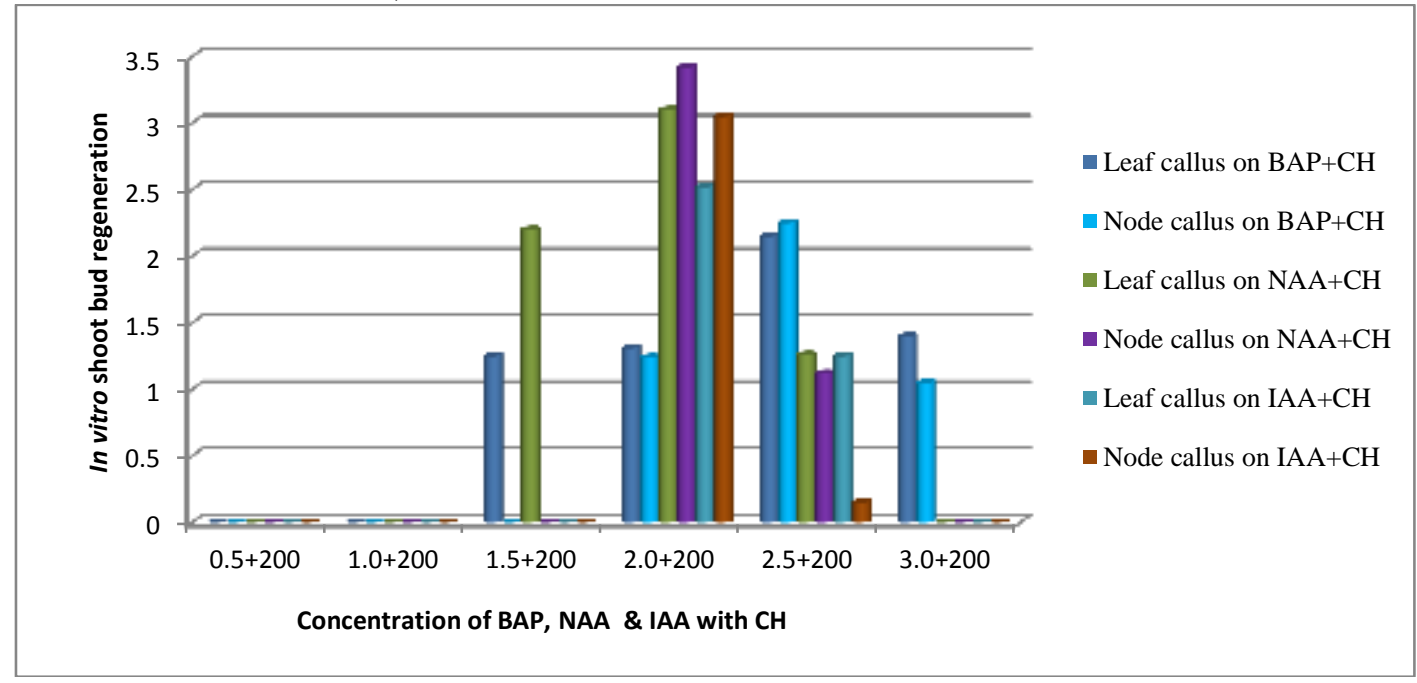

Fig 3:- In vitro shoot bud regeneration from callus, rooting, hardening and acclimatization of Pueraria tuberosa
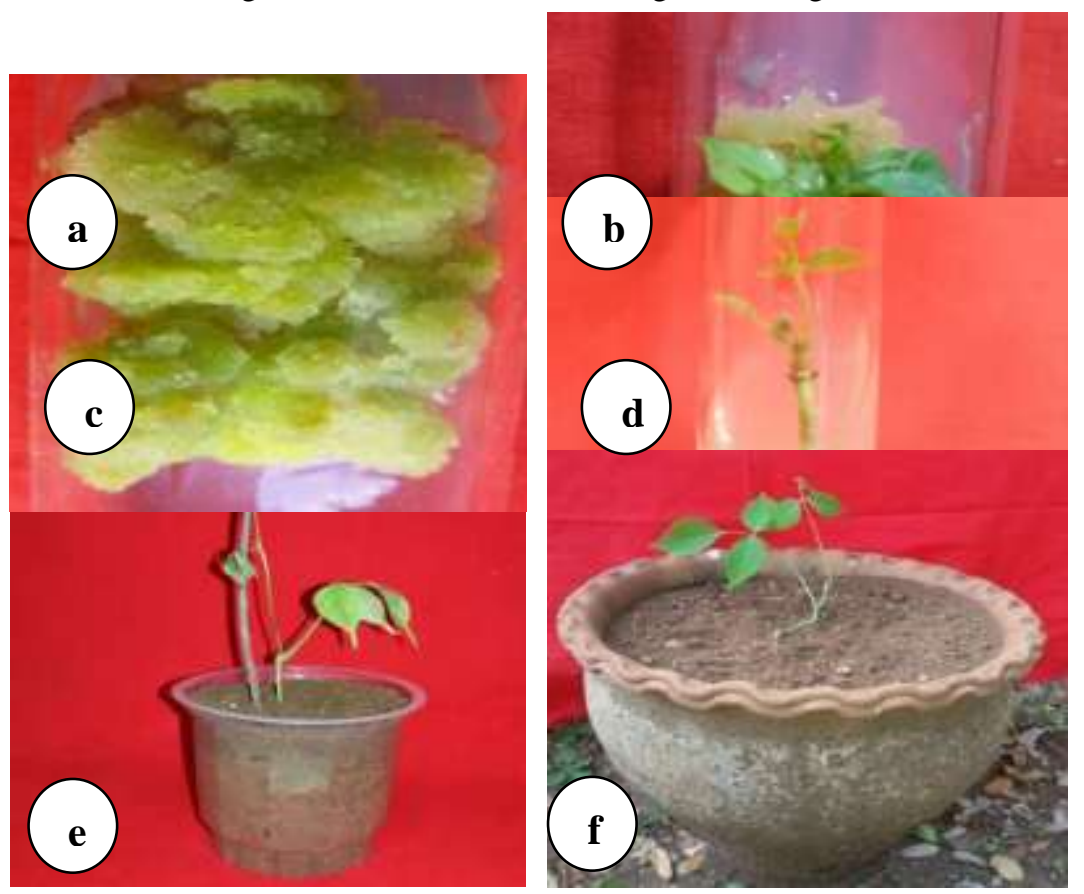

a. Induction of callus from nodal explant cultured on MS medium supplemented with $2.0 \mathrm{mg} / 1 \mathrm{NAA}+2.0 \mathrm{mg} / 1$ BAP

b. In vitro shoot bud regeneration from leaf derived callus cultured on MS medium supplemented with 2.0 mg/l $\mathrm{TDZ}+1.0 \mathrm{mg} / \mathrm{I} \mathrm{IAA}$

c. In vitro shoot bud regeneration from node derived callus cultured on MS medium supplemented with $2.0 \mathrm{mg} / 1$ $\mathrm{NAA}+200 \mathrm{mg} / \mathrm{l} \mathrm{CH}$

d. In vitro rooting from regenerated plantlets cultured on MS medium supplemented with $5.0 \mathrm{mg} / 1 \mathrm{IBA}$

e. Hardening of plantlets in polythin cup with soil (1:3) vermicompost

f. Acclimatization of plantlets in soil and vermicompost mixture. 


\section{References:-}

1. Whyte R.O., Nilsson-Leissner G and Trumble H.C, (1953). Legumes in Agriculture. FAO Agricultural Studies No. 21, Rome, 367 p.

2. Skerman P.J, (1977). Tropical Florage Legumes. FAO Plant Production and Protection Series no. 2, Rome.

3. Duck J.A, (1981). Handbook of legumes of world economic importance plenum Press, New York.

4. Kashyap M.K., V. Yadav, B.S. Sherawat S. Jain and S. Kumari et al., (2005). Different antioxidants status, total antioxidant power and free radicals in essential hypertension. Mol. Cell Biochem. 277: 89-99.

5. Kusano C and B. Ferrari, (2008). Total antioxidant capacity: A biomarker in biomedical and nutritional studies. J. Cell Mol. Biol., 7: 1-15.

6. Pandey N., J.K. Chaurasia, O.P. Tiwari and Y.B. Tripathi, (2007). Antioxidant properties of different fractions of tubers from Pueraria tuberosa Linn. Food Chem., 105: 219-222.

7. Bingham C., Beaman M., Nicholls AJ., Anthony PP, (1998). Necrotizing renal vasculopathy resulting in chronic renal failure after ingestion of methamphetamine and 3, 4-methylenedioxy-methamphetamine. Nephrology Dialysis Transplantation 13:2654-2655.

8. Khare CP (2007). Indian medicinal plants: An illustrated dictionary. ${ }^{\text {st }}$ ed. New York: Springer Science; p.527

9. Mamun A. N. K., Matin M. N., Bari M. A., Sidique N.A., Sultana R. S., Rahman M. H. \& Musa A. S. M, (2004).Micropropagation of Woody Legume (Albizia lebbeck) Through Tissue Culture. Pakistan Journal of Biological Sciences. 7 (7):109-103.

10. Veltcheva M.R., Svetleva D.L, (2005). In vitro regeneration of Phaseolus vulgaris L. via organogenesis from petiole explants. J Central European Agric 6:53-58.

11. Priyanka Pandey, Rakesh Mehta and Ravi Upadhyay, (2013). Effect of Explants Type and Different Plant Growth Regulators on Callus Induction and Plantlet Regeneration in Psoralea corylifolia [L]. I. J. R in Pharmaceutical and Biomedical Sciences. Vol. 4(3): 914-918.

12. Udomasuk L., Jarukamjorn K., Tanaka H and Putalum W, (2009). Production of isoflavonoids in Callus Cultures of Pueraria candollei var. mirifica, 64c, 239-243.

13. Varisai Mohamed, Shamsudeen; Sung, Jih-Min; Jeng, Toong-Long and Wang, Chang-Sheng, (2006). Organogenesis of Phaseolus angularis L.: high efficiency of advaentitious shoot regeneration from etiolated seedlings in the presence of N6-benzylaminopurine and thidiazuron. Plant Cell Tissue and Organ Culture, August, vol.86, no.2, p.187-199.

14. Tzitzikas E.N., Bergervoet M., Raemakers K., Vincken J.P., Lammeren A and Visser R.G.F (2004). Regeneration of pea (Pisum sativum L.) by a cyclic organogenic system. Plant Cell Reports 23: 453-461.

15. Shinde A.N., Malpathak N., Fulzele D.P, (2009). Induced high frequency shoot regeneration and enhanced isoflavones production in Psoralea corylifolia, Rec Nat Prod., 3:38-45.

16. Vasanth.K, Lakshmiprabha.A and Jayabalan.N, (2006). Amino acids enhancing plant regeneration from cotyledon and embryonal axis of peanut (Arachis hypogaea L.). Indian J. Crop Science, 1(1-2): 79-83.

17. Ugandhar T., Venkateshwarlu M., Shekhar G.P.V and Jagan Mohan Reddy K, (2012). High Frequency Somatic Embryogenesis and Plantlet Regeneration from Cotyledon Explants of Pigeon Pea (Cajanus Cajan (L.), A Grain Legume. International Journal of Pharma and Bio Sciences, 3(1), 55-63. 